\title{
Central diabetes insipidus
}

INSERM

\section{Source}

INSERM. (1999). Orphanet: an online rare disease and orphan drug data base. Central diabetes insipidus. ORPHA:178029

Central diabetes insipidus (CDI) is a hypothalamus-pituitary disease characterized by polyuria and polydipsia due to a vasopressin (AVP) deficiency. It can be inherited or acquired (hereditary CDI and acquired CDI; see these terms). 